\title{
Vision-Inspection System for Residue Monitoring of Ready-Mixed Concrete Trucks
}

\author{
Deok-Seok Seo, ${ }^{1}$ Baek-Joong Kim, ${ }^{2}$ and Myungdo Lee ${ }^{3}$ \\ ${ }^{1}$ School of Architecture, Halla University, 28 Halladae-gil, Wonju-si, Kangwon 220-712, Republic of Korea \\ ${ }^{2}$ Research Institute of Engineering and Technology, College of Engineering, Korea University, Anam-dong, Seongbuk-gu, \\ Seoul 136-713, Republic of Korea \\ ${ }^{3}$ Research and Development Center, Yunwoo Technology Co. Ltd., 48 Gangnam-daero 132-gil, Gangnam-gu, \\ Seoul 135-814, Republic of Korea \\ Correspondence should be addressed to Myungdo Lee; hg32lmd@korea.ac.kr
}

Received 1 May 2015; Accepted 21 June 2015

Academic Editor: João M. P. Q. Delgado

Copyright (C) 2015 Deok-Seok Seo et al. This is an open access article distributed under the Creative Commons Attribution License, which permits unrestricted use, distribution, and reproduction in any medium, provided the original work is properly cited.

\begin{abstract}
The objective of this study is to propose a vision-inspection system that improves the quality management for ready-mixed concrete (RMC). The proposed system can serve as an alternative to the current visual inspection method for the detection of residues in agitator drum of RMC truck. To propose the system, concept development and the system-level design should be executed. The design considerations of the system are derived from the hardware properties of RMC truck and the conditions of RMC factory, and then 6 major components of the system are selected in the stage of system level design. The prototype of system was applied to a real RMC plant and tested for verification of its utility and efficiency. It is expected that the proposed system can be employed as a practical means to increase the efficiency of quality management for RMC.
\end{abstract}

\section{Introduction}

Quality assurance of RMC is inevitably a major concern in any construction activity involving use of reinforced concrete. Due to its direct impact on structural safety, time, and cost, the quality of RMC is a critical factor required for achieving successful project outcomes. Therefore, it is essential that the RMC manufacturer has to ensure the quality of the RMC by inspecting the RMC delivery process.

Previous researches have been conducted on various aspects of quality control of RMC, which include provision of manuals for general management of concrete in batching plants and construction sites [1], RMC truck dispatch for transporting concrete to the site on time intended by the customer with high quality $[2,3]$, and optimal scheduling of transport of RMC $[4,5]$. Considering that controlling quality and time are the most essential factors for RMC, these previous studies contribute to providing framework for maintenance of quality and scheduling of RMC during procurement process.

However, improvement considerations are still detected in actual construction sites regarding quality and time management of RMC during procurement process. Generally, RMC manufactured in batching plant is mounted in RMC truck to be delivered to the construction site. The interior and exterior of RMC truck should be inspected by the manufacturer for any cleaning residues from the previously used RMC, including concrete waste and washing water, by visual inspection prior to loading the fresh RMC. Despite the effort to remove what can affect the quality of the fresh RMC, such residues cannot be easily detected from the deep and dark interior of the agitator drum. The current visual inspection method consumes more construction time than intended and results in delay in loading fresh RMC into the truck. 


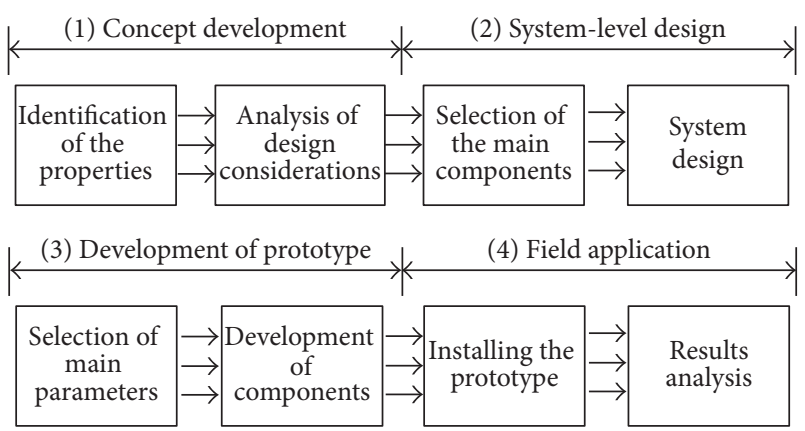

FIGURE 1: Research scope and process.

Therefore, this study aims to propose a vision-inspection system as an alternative to the current visual inspection method to ensure the quality and facilitate the scheduling of RMC. In order to present the system, design considerations during the system-level design process are first examined. Subsequently, structural elements of the system are determined from the derived design considerations. Finally, the prototype of the system is developed based on the concept development and system-level design processes. Through a field application, the operation performance and its efficiency are verified.

\section{System Design for Vision-Inspection System}

2.1. Design Process. This study presents a vision-inspection system that can serve as an alternative to the current visual inspection method for the detection of residues in agitator drum of RMC truck. The system is developed in accordance with the procedure for product development proposed by Ulrich and Eppinger (1999), which provides a systematic process that can minimize trial-and-errors in development stage [6]. The five major processes for product development include concept development, system-level design, detailed design, integration and improvement, and release. This study aims to develop the prototype after the system-level design and extend its scope to the application of the developed system on actual field, as shown in Figure 1.

First, the concept development stage can be divided into property identification of RMC and analysis of the design considerations of the inspection system. Property identification is executed by dividing the environmental considerations of vision-inspection system into hardware properties of RMC truck and the environmental conditions of RMC factory. Design requirement factors are subsequently derived from the previously identified properties in order to be utilized for the component specification of the vision-inspection system. Extensive interviews with managers of the batch plant and development engineers were conducted in order to derive the components. Second, system-level design stage includes analysis of the design considerations for selection of the components of vision-inspection system. Comprehensive understanding of the system is required in this stage, which thereby leads to the deduction of the optimal design plan by considering the feedback from the interviewed professionals.

2.2. Concept Development. As previously mentioned, concept development is classified into property identification and deduction of design considerations. First, the properties of RMC truck and conditions of RMC factory are first examined through the site surveys and consultations with experts from RMC manufacturers and managers. From these examinations, the properties and the design considerations were derived as follows.

(1) The properties of RMC truck and conditions of RMC factory are as follows.

(i) Opening diameter of agitator drum is $450 \mathrm{~mm}$.

(ii) Depth of the agitator drum is $3,500 \mathrm{~mm}$.

(iii) There is no lighting on the interior of the agitator drum.

(iv) Loading part of RMC and hopper of the agitator drum are located along the vertical line.

It is observed that the opening diameter of the agitator drum of the RMC truck is $450 \mathrm{~mm}$ with its depth as $3,500 \mathrm{~mm}$ in general, and its interior requires additional lighting to facilitate the visual inspection. Therefore, a digital camera with low light level and additional lamp with high intensity is necessary in the dark interior of the agitator drum for the system. Also, the loading part of RMC and hopper of the agitator drum are located along the vertical line during the supply of RMC, as shown in Figure 2. Therefore, automatic transfer equipment is needed for location movement of the camera during procurement and release processes of RMC.

Second, the properties of environmental conditions of the RMC plant are examined. From these examinations, the properties of environmental conditions and the design considerations are derived as follows.

(2) Environmental conditions of the RMC factory are as follows.

(i) A large quantity of dust and washing water of RMC is created, which accompanies continuous water-cleaning in the factory.

(ii) Noise and vibration should be under consideration.

(iii) Loading of fresh RMC should be executed in a short period of time.

A large amount of dust and washing water of RMC is created in the plant, which accompanies a substantial amount of water for cleaning and requires a system design in response to this factor. Furthermore, noise becomes a disturbance during the work where the RMC supply spot is located at a far distance from the control room, which demands for communication devices such as speaker and warning lights. These types of equipment will facilitate communication between the two places and expedite the inspection process. Figure 3 shows the link between the properties and the design considerations. 


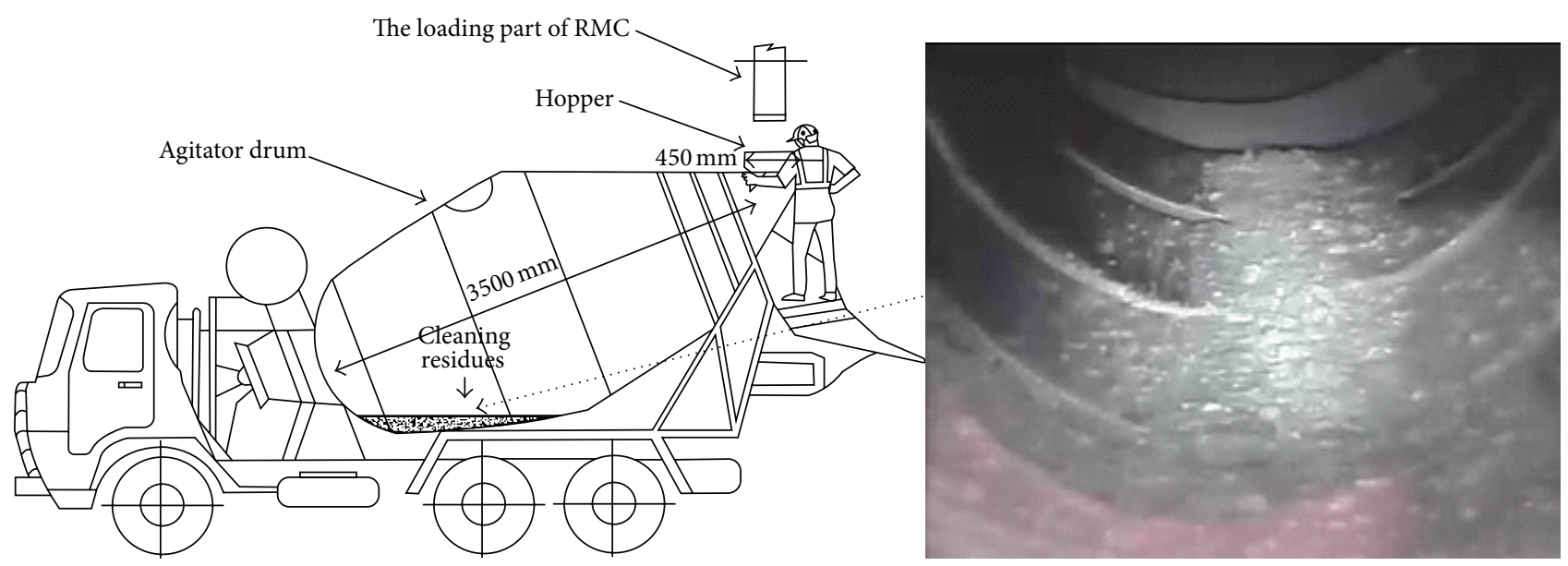

FIgURE 2: The shape of RMC truck and cleaning residues in the agitator drum.

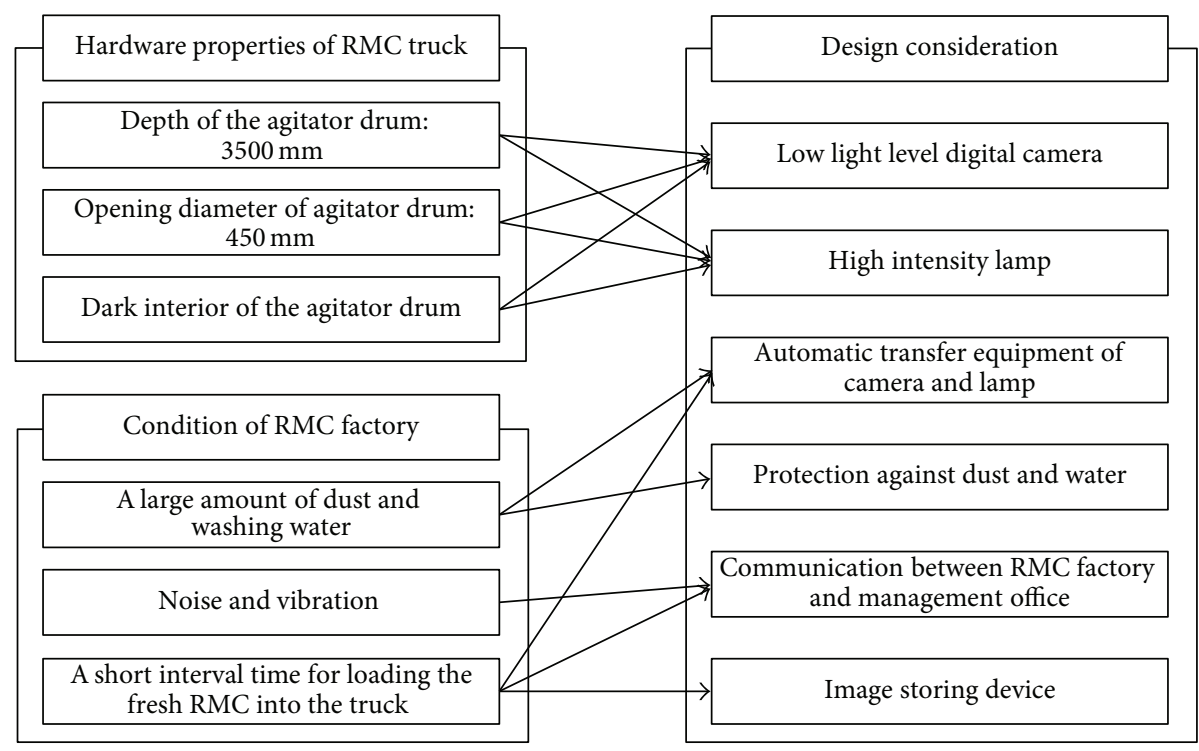

FIGURE 3: The major design considerations of the proposed system.

2.3. System-Level Design. In the stage of system-level design, design considerations of vision-inspection system are considered to select the components of the system. The following major components can be deduced: (1) image inspection device, (2) main system, (3) controller, (4) monitor, (5) image storing device, and (6) communication device. The configuration of six major components is shown in Figure 4.

The image inspection device is specifically designed to replace traditional visual inspection by workers. Low light level digital camera and lamp high intensity lamp are installed in the image inspection devices for observation of residues. Also, automatic transfer equipment is installed for the protection of camera within the housing and its temporary release during inspection process. Furthermore, housing is installed for the protection of inspection devices from cleaning residues of RMC. Figure 5 shows each component part of the image inspection device in the system.
Main system controls the power and operation of the entire system, while the site manager is in control of the controller for the management of transfer equipment in the control room. Also, the residues from the image inspection device are detected and then conveyed to the monitor. The images from the monitor are automatically saved in the image inspection device. Lastly, speaker, microphone, and warning lights are installed to facilitate communication between the control room and RMC supply spot.

\section{Development of the Prototype}

Prototype of the system is developed by considering the components derived from the concept development and system-level design processes. The image inspection device consists of a camera part and body portion, as shown in Figure 6. The camera part includes a wide angle lens 


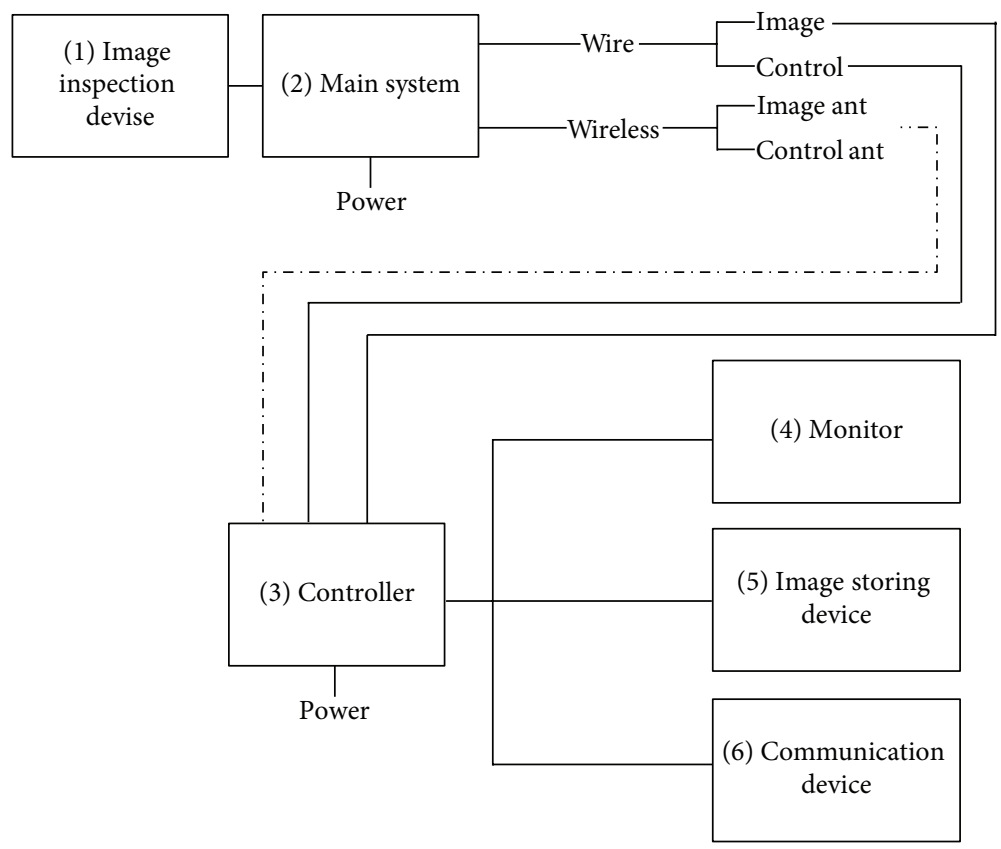

FIGURE 4: Configuration of the proposed system.

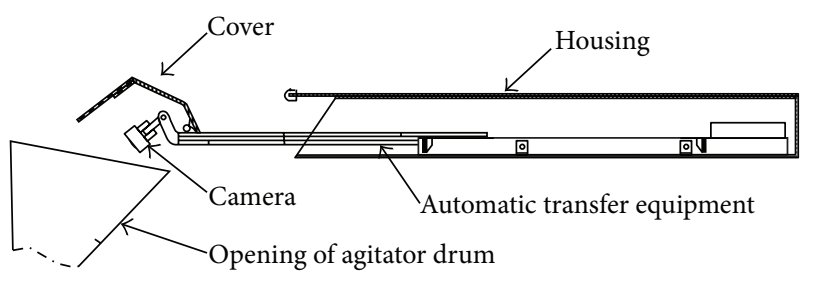

FIGURE 5: The sharp of image inspection device.

and two $1.2 \mathrm{~W}$ light-emitting diode (LED) lamps. This part achieves better image quality in the dark interior of the agitator drum. The body portion includes a cover, automatic transfer equipment with a worm gear to minimize vibration, and housing, as described in Section 2.3. The body portion has a waterproofing function to prevent malfunction and maximize its performance. Figure 6 shows each component of the prototype assigned to the configuration.

\section{Field Application}

4.1. Description of the Field Application. To verify the operation performance and the efficiency of the developed prototype by this research, a typical RMC plant, which has a control room, and one loading part were selected, and visual inspection was executed faithfully by workers. The total period of the application was 58 days excluding holidays (from March 1, 2014, to June 30, 2014). Figure 7 shows the image inspection device installed next to the loading part of RMC in plant.

4.2. Results and Discussion. The installed prototype performed a total of 415 inspections during 58 days, and residues have been detected in 103 cases, which is about $25 \%$ of the total. In particular, while it took 45 seconds to perform the conventional visual inspection, the proposed system performed the task within 11 seconds on average. This result showed that the inspection efficiency improved by about $76 \%$ (= $45-11$ seconds $/ 45$ seconds).

To evaluate utility and efficiency of the prototype, questionnaires were distributed to RMC manufacturer and operations managers. The users of the proposed system (two RMC manufacturers and nine operating managers) were asked to grade the satisfaction of reducing inspection time and accuracy, compared with the visual inspection, on the fivepoint Likert scale. The Likert scale is a scale of one to five: "1 = Highly Ineffective, 2 = Useless, 3 = Moderately Useful, 4 = Highly Useful, and $5=$ Highly Effective." The results of the questionnaire indicated a remarkable improvement in inspection time by scoring an average of 4.5 points and also in accuracy improvement by scoring an average of 4.0 points. These results show that the system proposed in this study can be employed as a practical means to increase the efficiency of quality management for RMC.

\section{Conclusion}

This paper proposes the development of vision-inspection system for detection of residues in agitator drum of RMC truck that can serve as an alternative to the current visual inspection. To verify its performance and feasibility, it was applied to an actual RMC plant. The proposed system showed stable performance for inspection as well as a high level of satisfaction with its feasibility.

Further application of the improvement considerations, which are derived from continuous field management to the proposed prototype, can be achieved. In addition, future 


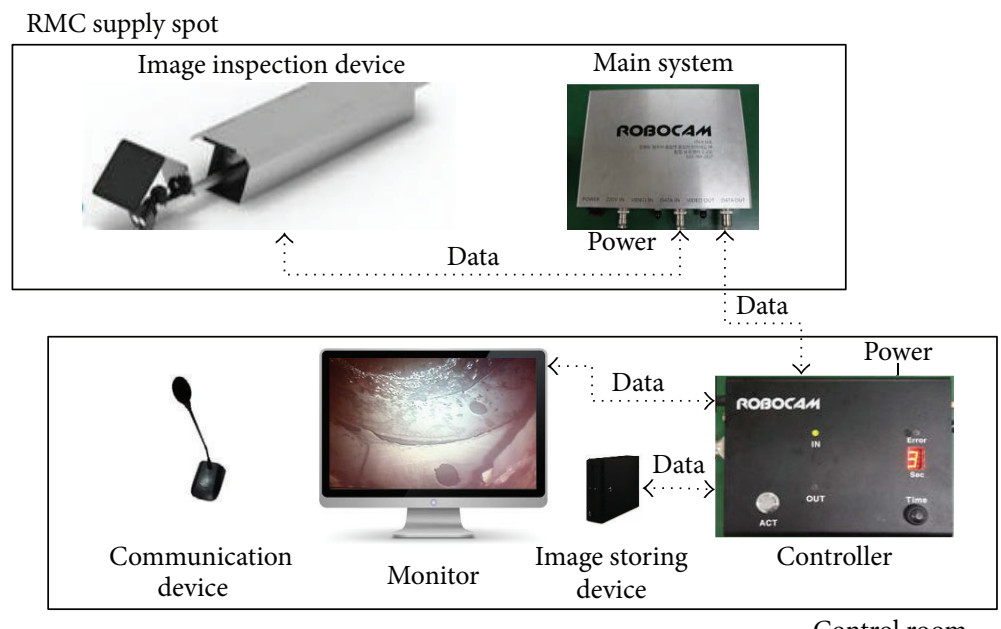

FIGURE 6: System diagram of the prototype.

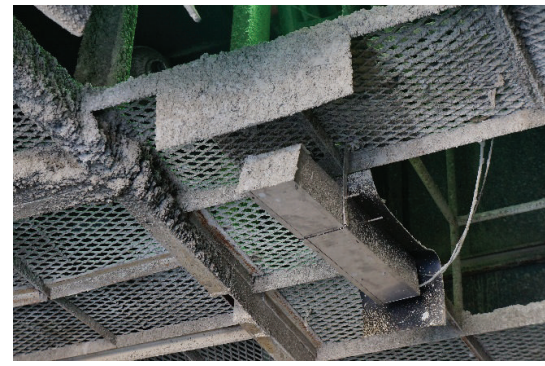

Standby status

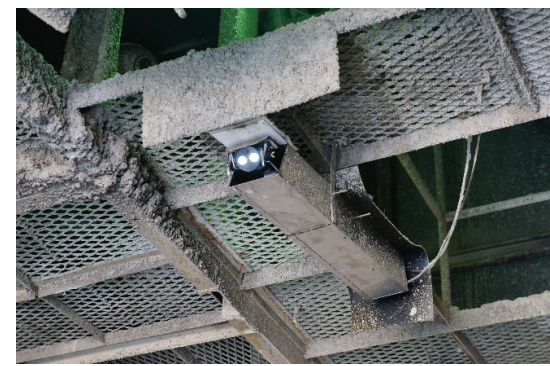

Starting status

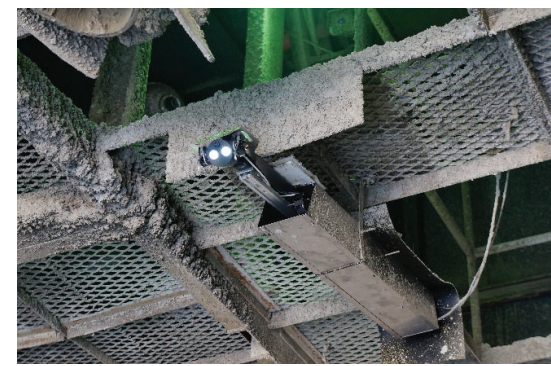

Inspection status

FIGURE 7: Operating status of the prototype.

research is expected to conduct cost-effectiveness analysis of the system based on long-term field observation and management.

\section{Conflict of Interests}

The authors declare that there is no conflict of interests regarding the publication of this paper.

\section{References}

[1] R. Anderson, R. Anderson, and J. D. Dewar, Manual of ReadyMixed Concrete, CRC Press, 2003.

[2] S. Yan, W. Lai, and M. Chen, "Production scheduling and truck dispatching of ready mixed concrete," Transportation Research Part E: Logistics and Transportation Review, vol. 44, no. 1, pp. 164-179, 2008.

[3] D. Naso, M. Surico, B. Turchiano, and U. Kaymak, "Genetic algorithms for supply-chain scheduling: a case study in the distribution of ready-mixed concrete," European Journal of Operational Research, vol. 177, no. 3, pp. 2069-2099, 2007.

[4] L. D. Graham, D. R. Forbes, and S. D. Smith, "Modeling the ready mixed concrete delivery system with neural networks," Automation in Construction, vol. 15, no. 5, pp. 656-663, 2006.
[5] W. Min and L. S. Pheng, "Modeling just-in-time purchasing in the ready mixed concrete industry," International Journal of Production Economics, vol. 107, no. 1, pp. 190-201, 2007.

[6] K. T. Ulrich and S. D. Eppinger, Product Design and Development, McGraw-Hill, 1999. 

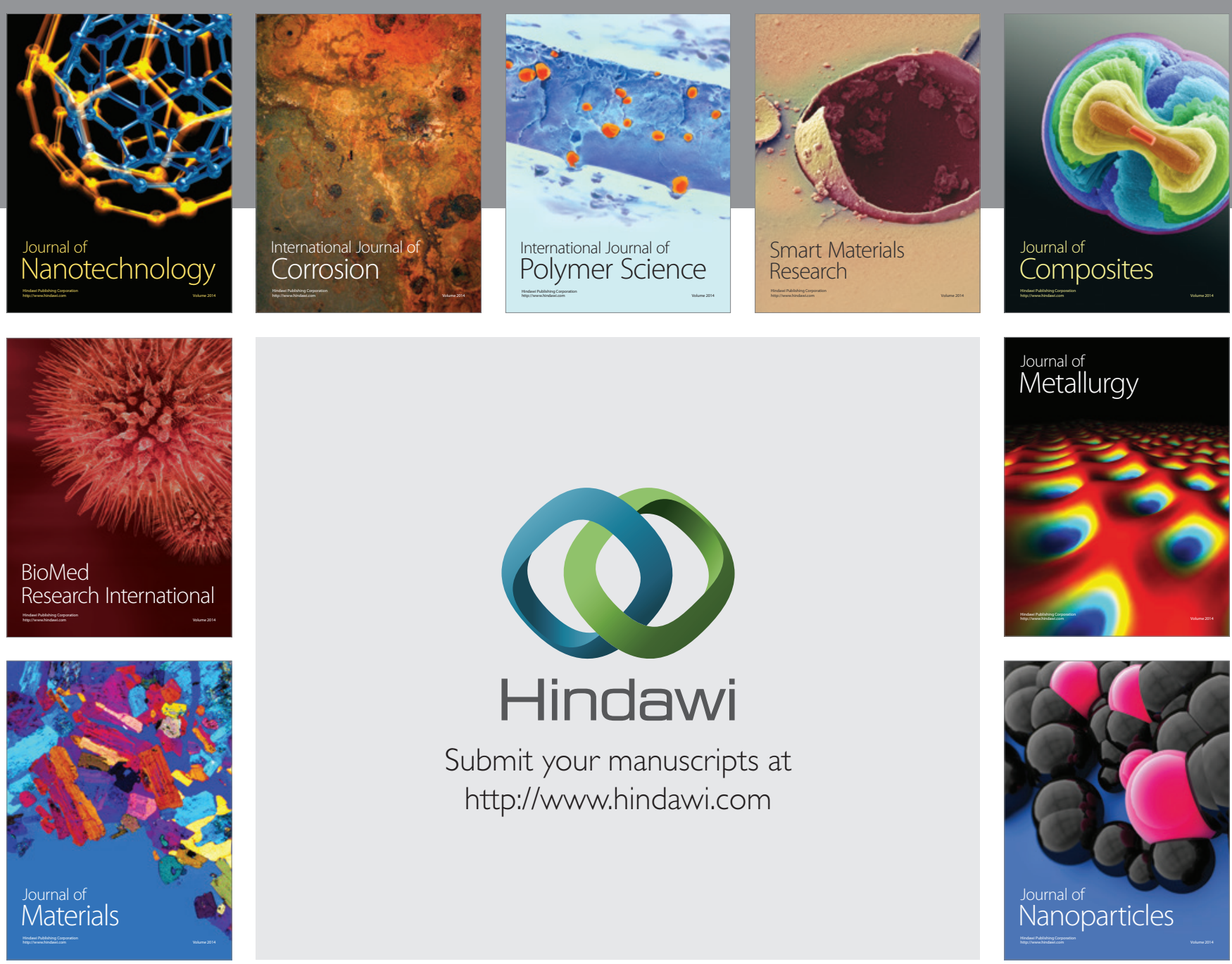

Submit your manuscripts at http://www.hindawi.com
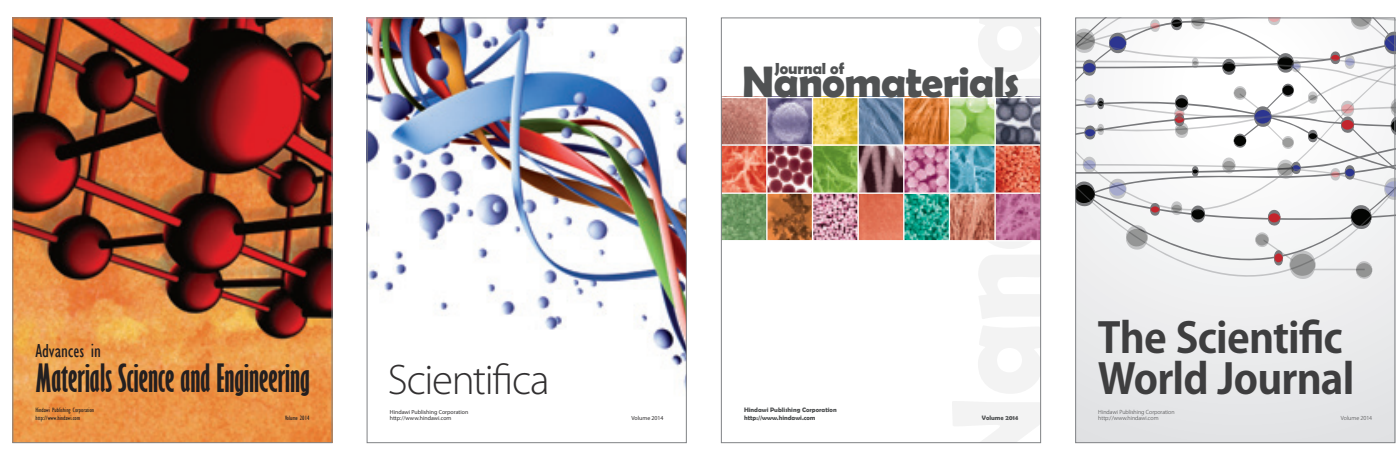

\section{The Scientific World Journal}
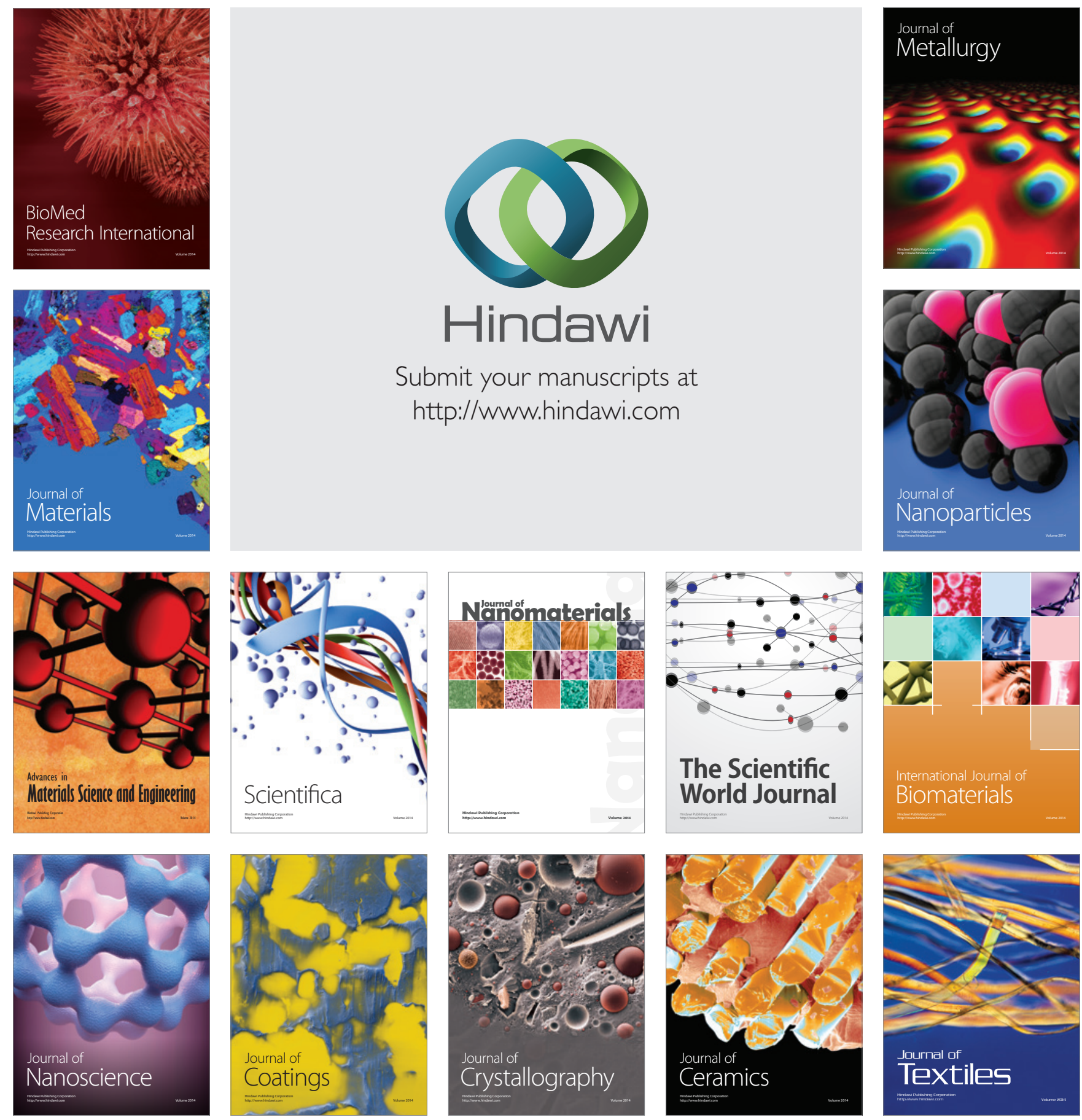